\title{
Possible association of tumor necrosis factor receptor 2 gene polymorphism with severe hypertension using the extreme discordant phenotype design
}

\author{
Takashi Eguchi $^{1}$, Tatsuya Maruyama ${ }^{1}$, Yoichi Ohno ${ }^{1,2}$, Toshiyuki Morii ${ }^{1}$, Keiichi Hirao ${ }^{1}$, Hiroshi Hirose ${ }^{3}$, \\ Hiroshi Kawabe ${ }^{3}$, Ikuo Saito ${ }^{3}$, Matsuhiko Hayashi ${ }^{1}$ and Takao Saruta ${ }^{1}$
}

The tumor necrosis factor (TNF)- $\alpha$ pathway has a key role in regulating insulin resistance. TNF receptor 2 (TNFR2) is an emerging candidate gene for insulin resistance in essential hypertension. We examined the association of insulin resistance and enhanced TNF pathway with severe hypertension and the association of a microsatellite polymorphism of the TNFR2 gene with severe hypertension. Male severe essential hypertensive patients (HT) with the onset before 60 years of age and with genetic predispositions to hypertension were consecutively enrolled at our outpatient department $(N=92)$. Normotensive men (NT) over 50 years of age were randomly registered from the participants in the annual health check program $(N=78)$. Patients were selected as HT and NT who met stringent criteria for systolic/diastolic blood pressure (SBP/DBP) levels $\geqq 180$ and/or $110 \mathrm{~mm} \mathrm{Hg}$ and $<120 / 80 \mathrm{~mm} \mathrm{Hg}$, respectively. HT revealed significantly higher plasma insulin levels, C-reactive protein (CRP) and soluble fraction of TNFR2 concentrations (sTNFR2) than NT. A microsatellite polymorphism of the CA repeat in intron 4 of the TNFR2 gene was analyzed. The allele frequency of CA16 in HT differed significantly from that in NT (66/184 vs. 36/156, $P=0.01$ by $\chi^{2}$ analysis). In HT, the CA16 carriers showed significantly higher SBP and plasma insulin levels and a higher tendency of sTNFR2 than did those without this allele. In NT, CA16 carriers revealed significantly higher sTNFR2 and CRP levels than did the CA16 non-carriers. These results suggest that the TNFR2 gene locus has a potential effect on developing severe hypertension through the augmented TNF pathway and insulin resistance.

Hypertension Research (2009) 32, 775-779; doi:10.1038/hr.2009.91; published online 26 June 2009

Keywords: extreme discordant phenotypes; insulin resistance and C-reactive protein; soluble tumor necrosis factor receptor 2

\section{INTRODUCTION}

Concern has been increasing about the association between essential hypertension and metabolic disorders because hypertension occasionally leads to cardiovascular complications. ${ }^{1}$ Accumulating evidence suggests that atherosclerosis is derived from metabolic disorders and accompanies the activation of inflammation. ${ }^{2,3}$ Chronic subclinical inflammation is associated with arterial stiffness in essential hypertension $^{4,5}$ and precedes its onset. ${ }^{6}$ Tumor necrosis factor (TNF)- $\alpha$, once regarded as a cytokine involved in the regulation of the immune system, is now known to participate in insulin resistance. ${ }^{7,8}$ TNF- $\alpha$ is hypothesized to have a key role in the pathophysiology of insulin resistance associated with essential hypertension.

Tumor necrosis factor- $\alpha$ expresses its various effects through the binding of two types of TNF receptors, TNFR1 (p55) and TNFR2 (p75). ${ }^{9}$ TNFR1 signals universal activities of TNF- $\alpha$, whereas TNFR2 mainly signals metabolic actions. ${ }^{10}$ Circulating soluble TNFR2 (sTNFR2) is shed by proteolytic cleavage from the cell surface and is proposed to buffer TNF- $\alpha$ on the metabolic pathway. ${ }^{11}$ sTNFR2 is considered to block TNF- $\alpha$ activity at high concentrations, but to preserve TNF activity by stabilizing its long-term activity at low concentrations. The ratio of sTNF- $\alpha$ receptors (sTNFR2/sTNFR1) has recently been reported to correlate with systolic and diastolic blood pressure levels (SBP and DBP, respectively). Increased circulating sTNFR2, but not sTNFR1 or TNF- $\alpha$, concentrations were reportedly associated with insulin resistance in healthy volunteers, lean nondiabetic offspring of diabetic patients, and young obese patients. ${ }^{8,10}$ Therefore, the sTNFR2 concentration reflects the degree of activation of the TNF pathway and is a surrogate marker of insulin resistance.

We showed that impaired insulin sensitivity is associated with the offspring of essential hypertensives. ${ }^{12}$ Whole-body insulin resistance accompanies cellular insulin resistance in immortalized lymphoblasts derived from young, lean hypertensive patients. ${ }^{13}$ These previous findings indicate that insulin resistance associated with essential hypertension results from a genetic abnormality. The polymorphisms

${ }^{1}$ Department of Internal Medicine, School of Medicine, Keio University, Saitama Prefecture, Japan; ${ }^{2}$ Community Health Science Center, Saitama Medical University, Saitama Prefecture, Japan and ${ }^{3}$ Health Center, Keio University, Yokohama, Japan

Correspondence: Dr Y Ohno, Department of Internal Medicine, School of Medicine, Keio University, 38 Morohongo, Moroyama-machi, Iruma-gun, Saitama Prefecture 350-0495, Japan.

E-mail: yo1-ohno@bk2.so-net.ne.jp

Received 2 March 2009; revised 29 May 2009; accepted 1 June 2009; published online 26 June 2009 
in the $3^{\prime}$-untranslated region of the TNFR2 gene (TNFRSF1B) were also linked with obesity, leptin concentrations and insulin resistance in type 2 diabetic patients. ${ }^{14}$ Glenn et al. ${ }^{15}$ reported that a haplotype including a microsatellite marker consisting of 16 CA repeats in intron 4 of the TNFR2 gene was associated with genetic hypertension and higher plasma sTNFR2 concentrations in the case-control study. However, the same group refuted the association of the microsatellite polymorphism with essential hypertension in a later larger-scale study, although the statistical significance is marginal. ${ }^{16}$ In this situation, an earlier probability for the association of the microsatellite in the TNFR2 gene with essential hypertension can be estimated.

The false-positive report probability is a formidable issue to accomplish a case-control association study with a small sample size. ${ }^{17}$ To raise both the sensitivity and the specificity of a genetic association study, we have been advocating the importance of selective genotyping with extreme discordant phenotypes (EDPs). ${ }^{13,18}$ The statistical power of association using the EDP design is estimated as more than double when the sum of the upper and lower selection areas was 0.2. ${ }^{19,20}$ Another advantageous procedure is to design a study with a relatively high prior probability $(P=0.01-0.25) .{ }^{17}$ Enrolling appropriate patients whose intermediate phenotypes are suitable with the pathophysiological pathway relevant to the candidate gene also contributes to raising prior probability and reducing false-positive report probability. In this study, we investigated the relationship between insulin resistance and the TNF pathway and the association of the CA repeat polymorphisms in the TNFR2 gene with severe hypertension. Here, we propose a novel application of a case-control association study with a small sample size to the analysis of a relatively high prior probability using the EDP design.

\section{METHODS}

\section{Study population}

Hypertensive patients (HT) were consecutively recruited among outpatients between 2000 and 2003 at Keio University Hospital. Recruitment was confined to patients who met all the following criteria: pretreatment for $\mathrm{SBP} \geqq 180 \mathrm{~mm} \mathrm{Hg}$ and/or $\mathrm{DBP} \geqq 110 \mathrm{~mm} \mathrm{Hg}$, at least one hypertensive parent, male gender, and onset of hypertension before 60 years of age. BP measurement was performed according to the method described previously. ${ }^{12}$ The proportions of HT receiving calcium channel blockers, angiotensin-converting enzyme inhibitors or angiotensin receptor blockers, and thiazide diuretics were 74, 65 and $25 \%$, respectively. Patients with diabetes, or heart, renal or endocrinological disease were excluded. Secondary hypertension was excluded by clinical symptoms and physical and laboratory examinations including routine blood chemistry and adrenal function, if necessary. Healthy volunteers were also consecutively recruited among individuals undergoing an annual health examination at Keio University. Normotensive men (NT) who met the following criteria were randomly registered: $\mathrm{SBP}<120 \mathrm{~mm} \mathrm{Hg}$ and $\mathrm{DBP}<80 \mathrm{~mm} \mathrm{Hg}$; male gender, age over 50 years, and no familial history of hypertension among their first-degree relatives. Patients with acute intercurrent illnesses and chronic inflammatory diseases were also excluded. With these BP levels and genetic predispositions to hypertension, $\mathrm{HT}$ and NT were assumed to have extreme phenotypes of genetic hypertension that are consistent with less than 5 and $10 \%$ of the general population at their age, respectively. ${ }^{21,22}$ This study was conducted according to the principles expressed in the Declaration of Helsinki. The Ethics Review Committee of Keio University School of Medicine approved the protocol. Each patient gave informed consent in writing before enrollment.

\section{Genotyping}

Genotyping was performed only in the registered HT and NT. Leukocyte DNA was extracted for genotyping by PCR. The following primers were used: forward, 5'-GTGATCTGCAAGATGAACTCAC-3' labeled at the $5^{\prime}$-end with 6-FAM; reverse, 5'-ACACCACGTCTGATGTTTCA-3'. Each 20- $\mu \mathrm{l}$ aliquot of PCR mix contained $10 \mathrm{ng}$ of genomic DNA, $100 \mathrm{pmol}$ of each primer, a
$2.5 \mathrm{mmoll}^{-1}$ concentration of each dNTP, $0.5 \mathrm{U}$ of TaKaRa Ex Taq DNA polymerase (TaKaRa Bio, Tokyo, Japan), $100 \mathrm{mmoll}^{-1} \mathrm{KCl}, 10 \mathrm{mmoll}^{-1}$ Tris$\mathrm{HCl}\left(\mathrm{pH} 8.0\right.$ ) and $20 \mathrm{mmoll}^{-1} \mathrm{MgCl}_{2}$. After initial incubation at $95^{\circ} \mathrm{C}$ for $12 \mathrm{~min}, 35$ cycles were carried out at $94^{\circ} \mathrm{C}$ for $1 \mathrm{~min}, 60^{\circ} \mathrm{C}$ for $1 \mathrm{~min}$ and $72^{\circ} \mathrm{C}$ for $1 \mathrm{~min}$, followed by 15 cycles at $94^{\circ} \mathrm{C}$ for $1 \mathrm{~min}, 58^{\circ} \mathrm{C}$ for $1 \mathrm{~min}$ and $72^{\circ} \mathrm{C}$ for $1 \mathrm{~min}$; then 20 cycles at $94^{\circ} \mathrm{C}$ for $1 \mathrm{~min}, 55^{\circ} \mathrm{C}$ for $1 \mathrm{~min}$ and $72^{\circ} \mathrm{C}$ for $1 \mathrm{~min}$; and finally incubation at $72^{\circ} \mathrm{C}$ for $30 \mathrm{~min}$. The PCR products were electrophoresed using an ABI 3700 automated sequencer (Applied Biosystems, Foster City, CA, USA), and genotypes were assigned using ABI Genotyper software. Alleles were visualized as 263-, 265-, 267-, 269-, 271-, 273- and 275bp PCR products. The seven alleles were termed CA11, CA12, CA13, CA14, CA15, CA16 and CA17, respectively, to indicate the number of CA repeats.

\section{Plasma assays}

Plasma concentrations of TNF- $\alpha$ and sTNFR2 were measured using a Quantikine HS human TNF- $\alpha$ immunoassay and a Quantikine human sTNFR2 immunoassay (R\&D Systems, Minneapolis, MN, USA), respectively. Plasma C-reactive protein (CRP) concentrations were measured using an $\mathrm{N}$ High Sensitivity CRP kit (Dade Behring, Marburg, Germany). All other blood determinations were performed by using routine clinical methods as previously described. ${ }^{13}$

\section{Statistical analysis}

Allele frequencies between the genotype groups and the proportions of the major allele carriers in the TNFR2 gene were assessed by using the $\chi^{2}$-test for Hardy-Weinberg equilibrium. $\chi^{2}$ analysis followed by Fischer's exact test was used to estimate the contribution of the microsatellite polymorphism in the TNFR2 gene to HT. We then examined the association of the major alleles (CA15, CA16) with HT. Non-parametric approaches were adopted to compare the biomarkers because the distributions of all the biomarkers were right skewed and the Kolmogorov-Smirnov statistic indicated that some of the distributions of the biomarkers were not normal even after logarithmic transformation. The Mann-Whitney test was used to compare the biomarkers between HT and NT. Correlations between clinical parameters were assessed by Spearman's method in HT and in NT, separately. Next, the Mann-Whitney test was also performed to compare the biomarkers between CA16 carriers and CA16 non-carriers in HT and between CA16 carriers and CA16 non-carriers in NT, separately. Statistical analyses were performed using the SPSS statistical program (SPSS V15, SPSS Inc, Chicago, IL, USA).

\section{RESULTS}

\section{Comparisons of clinical parameters between HT and NT}

Clinical characteristics of HT and NT are summarized in Table 1. Body mass index (BMI) and waist-to-hip ratio were significantly greater in HT than in NT. Fasting plasma glucose, immunoreactive insulin levels and homeostasis model assessment of insulin resistance index (HOMA-R) were significantly higher in HT than in NT, whereas hemoglobin A1c levels were similar between the groups. Triglyceride concentrations were significantly higher in HT than in NT, and highdensity lipoprotein-cholesterol concentrations were significantly lower in HT than in NT. Uric acid concentrations were significantly higher in HT than in NT, whereas plasma sodium, potassium, creatinine and urea nitrogen levels were similar between groups (data not shown). These results clarify that HT were more insulin resistant than NT. White blood cell count and high sensitivity CRP concentrations were significantly higher in HT than in NT. Plasma TNF- $\alpha$ concentrations were significantly lower in HT than in NT; however, sTNFR2 levels were significantly higher in HT than in NT. These results indicate that HT showed augmented inflammatory process through the TNF pathway.

\section{Correlations between clinical parameters}

In HT, BMI was significantly correlated with SBP, DBP, HOMA-R, immunoreactive insulin and CRP levels $(r=0.241, P<0.05 ; r=0.267$, 
Table 1 Clinical characteristics of hypertensive patients and normotensive controls

\begin{tabular}{|c|c|c|c|}
\hline & $\begin{array}{c}\text { Hypertensive } \\
\text { patients } \\
(\mathrm{N}=92)\end{array}$ & $\begin{array}{c}\text { Normotensive } \\
\text { controls } \\
(\mathrm{N}=78)\end{array}$ & $\begin{array}{l}\text { P-value } \\
\text { by Mann- } \\
\text { Whitney }\end{array}$ \\
\hline \multicolumn{4}{|l|}{ Clinical characteristics } \\
\hline Age (years) & $48-55-60$ & $53-55-60$ & 0.22 \\
\hline Systolic BP (mm Hg) & 170-182-192 & 104-109-117 & $<0.0001$ \\
\hline Diastolic BP $(\mathrm{mm} \mathrm{Hg})$ & $110-112-123$ & $66-71-75$ & $<0.0001$ \\
\hline Heart rate (beats $\mathrm{min}^{-1}$ ) & 68-70-79 & $65-69-75$ & 0.02 \\
\hline Body mass index $\left(\mathrm{kg} \mathrm{m}^{-2}\right)$ & $24.1-25.3-26.8$ & 20.9-22.2-23.9 & $<0.0001$ \\
\hline Waist-to-hip ratio & $0.88-0.91-0.92$ & $0.85-0.88-0.91$ & 0.02 \\
\hline \multicolumn{4}{|l|}{ Metabolic parameters } \\
\hline Glucose (mg per $100 \mathrm{ml})$ & $101-110-122$ & 90-96-104 & $<0.0001$ \\
\hline IRI $\left(\mathrm{U} \mathrm{ml}^{-1}\right)$ & 5.3-9.0-13.0 & $2.6-3.2-4.1$ & $<0.0001$ \\
\hline HOMA-R & $1.4-2.5-3.6$ & $0.62-0.76-1.1$ & $<0.0001$ \\
\hline Hemoglobin A1c (\%) & $4.7-5.0-5.2$ & $4.7-4.8-5.1$ & 0.53 \\
\hline TC (mg per $100 \mathrm{ml}$ ) & $175-206-225$ & 189-210-222 & 0.40 \\
\hline LDL-C (mg per $100 \mathrm{ml})$ & $92-120-137$ & $102-126-139$ & 0.03 \\
\hline Triglyceride (mg per $100 \mathrm{ml}$ ) & 95-131-194 & $62-84-155$ & $<0.0001$ \\
\hline HDL-C (mg per $100 \mathrm{ml}$ ) & $43-50-53$ & $51-58-68$ & $<0.0001$ \\
\hline Uric acid (mg per $100 \mathrm{ml}$ ) & $6.1-6.5-7.2$ & $5.3-6.0-6.5$ & $<0.0001$ \\
\hline \multicolumn{4}{|l|}{ Inflammatory factors } \\
\hline WBC count $\left(\times 10^{3} / \mathrm{mm}^{3}\right)$ & $5.2-5.9-6.1$ & $4.6-5.3-6.1$ & $<0.0001$ \\
\hline CRP (ng ml-1) & $0.35-0.66-1.62$ & $0.20-0.28-0.61$ & $<0.0001$ \\
\hline TNF- $\alpha\left(\mathrm{pg} \mathrm{ml}^{-1}\right)$ & $1.3-1.8-2.5$ & $1.8-2.3-3.0$ & 0.001 \\
\hline Soluble TNFR2 ( $\mathrm{ng} \mathrm{ml}^{-1}$ ) & $1.62-1.85-2.53$ & $1.42-1.57-1.72$ & $<0.0001$ \\
\hline
\end{tabular}

Abbreviations: BP, blood pressure; CRP, high-sensitivity C-reactive protein; IRI, immunoreactive insulin; LDL-C, low-density lipoprotein-cholesterol; HDL-C, high-density lipoprotein-cholesterol; HOMA-R, homeostasis model assessment of insulin resistance index; NS, not significant; TC, total cholesterol; TNF, tumor necrosis factor; TNFR2, tumor necrosis factor type 2 receptor; WBC, white blood cell.

Data are expressed as 25 percentile-median-75 percentile.

$P<0.01 ; r=0.266, P<0.05 ; r=0.271, P<0.01 ;$ and $r=0.264, P<0.05$, respectively). Similarly, HOMA-R was significantly correlated with sTNFR2 concentrations in HT $(r=0.381, P<0.01)$. In NT, BMI was significantly correlated with SBP, DBP, HOMA-R and immunoreactive insulin levels $(r=0.389, P<0.0001 ; r=0.290, P<0.01 ; \quad r=0.608$, $P<0.0001$; and $r=0.587, \quad P<0.0001$, respectively). Similarly, HOMA-R was significantly correlated with CRP levels and sTNFR2 concentrations in NT $(r=0.229, P<0.05$ and $r=0.423, P<0.0001$, respectively). Therefore, both in $\mathrm{HT}$ and NT, BP is related to insulin resistance, which is tightly linked to altered TNF pathway.

\section{TNFR2 gene polymorphisms and insulin resistance}

Seven alleles (CA11 to CA17) were identified in the CA repeats of the microsatellite marker in intron 4 of the TNFR2 gene in which genotype frequencies satisfied the Hardy-Weinberg equilibrium. The allele frequencies in HT significantly differed from those in NT ( $P=0.01, \chi^{2}$ analysis followed by Fischer's exact test) (Table 2$)$. The common alleles were CA15 and CA16. The allele frequencies of CA15 and CA16 in HT differed markedly from those in NT (CA15, 76/184 vs. $85 / 156, P=0.02$ by $\chi^{2}$ analysis, and CA16, 66/184 vs. $36 / 156$, $P=0.01$ by $\chi^{2}$ analysis). We focused on the relationship between CA16 and HT. The odds ratio having the CA16 allele of HT compared with NT is calculated as $52^{\star} 48 / 30^{\star} 40=2.08$ ( $95 \%$ confidence interval 1.12-3.85). Clinical characteristics of CA16 allele carriers and CA16 non-carriers are compared in HT and NT, separately. In HT, SBP, HOMA-R, immunoreactive insulin and low-density lipoprotein-
Table 2 Allele frequency of the CA repeats in intron 4 of the TNFR2 gene in hypertensive patients and normotensive controls

\begin{tabular}{lccl}
\hline CA repeats & $\begin{array}{c}\text { Hypertensive patients } \\
(\mathrm{N}=92,184 \text { alleles })\end{array}$ & $\begin{array}{c}\text { Normotensive controls } \\
(\mathrm{N}=78,156 \text { alleles })\end{array}$ & P-value \\
\hline CA11 & $18(10 \%)$ & $11(7 \%)$ & \\
CA12 & $2(1 \%)$ & $2(1 \%)$ & 0.01 \\
CA13 & $3(2 \%)$ & $1(1 \%)$ & \\
CA14 & $7(4 \%)$ & $9(6 \%)$ & \\
CA15 & $76(41 \%)$ & $36(23 \%)$ & \\
CA16 & $66(36 \%)$ & $12(8 \%)$ & \\
CA17 & $12(7 \%)$ & & \\
\end{tabular}

Abbreviation: TNFR2, tumor necrosis factor type 2 receptor.

$P$-value was assessed by $\chi^{2}$ analysis followed by Fischer's exact test.

cholesterol levels were significantly higher in CA16 carriers than in CA16 non-carriers $(P<0.001, P<0.001, P<0.01$ and $P<0.05$, respectively) and sTNFR2 showed a similar tendency $(P=0.1)$. In NT, CRP and sTNFR2 levels were significantly higher in CA16 carriers than in CA16 non-carriers $(P<0.05$ and $P<0.05$, respectively), although plasma TNF- $\alpha$ concentrations were similar between the groups.

\section{DISCUSSION}

In this study, we confirmed that insulin resistance and the augmented TNF pathway are tightly linked with severe hypertension with genetic predispositions. In the TNF pathway, sTNFR2 is of clinical importance in insulin resistance as well as in inflammation. We also showed that the CA16 microsatellite polymorphism in intron 4 of the TNFR2 gene is significantly associated with severe hypertension in a small sample case-control study using the EDP design. The CA16 microsatellite polymorphism in the TNFR2 gene is likely to be associated with higher sTNFR2 concentrations and higher CRP levels in NT. These findings suggest that the TNFR2 gene locus has a potential effect on contributing to the enhanced TNF pathway and insulin resistance, which could develop severe hypertension accompanied by atherosclerosis through an augmented inflammatory process. Several studies have indicated that insulin resistance, in association with essential hypertension, has a genetic component. ${ }^{12,13,23}$ However, only a few studies have successfully shown that a mutation is associated with phenotypes that are related to insulin resistance and associated with hypertension. ${ }^{24-27}$ This study indicates that the CA16 microsatellite polymorphism in the TNFR2 gene is a potential marker for severe hypertension associated with insulin resistance.

As not only monocytes but also adipocytes express TNF- $\alpha$, involvement of the TNF- $\alpha$ pathway has been suspected in the pathogenesis of hypertension, dyslipidemia and insulin resistance. Earlier studies have shown that a higher concentration of TNF- $\alpha$ is associated with type 2 diabetes mellitus ${ }^{28}$ and that TNF- $\alpha$ production by adipose tissue is accelerated in obesity. ${ }^{29}$ Recent studies have indicated that plasma TNF- $\alpha$ is unstable and that sTNFR2 levels represent a more sensitive marker of TNF pathway activity. ${ }^{11,28}$ Their findings for sTNFR2 are consistent with this study. However, our finding that the TNF- $\alpha$ levels were lower in HT than in NT is inconsistent with the earlier studies. This might be attributable to the instability of TNF- $\alpha$ measurement and the reciprocal influence of the higher sTNFR2 levels in HT. TNF- $\alpha$ markedly upregulates the expression of TNFR2 mRNA at the lower concentrations. TNFR 2 is thought to mediate signaling by membranebound ligands in immune and endothelial cells. ${ }^{30}$ When TNF- $\alpha$ binds to TNF receptors, the receptor's N-terminal extracellular domain is shed to produce soluble TNF receptors. These receptors inhibit TNF 
effects at high concentrations of TNF- $\alpha$ but increase the long-term effects of TNF- $\alpha$ at lower concentrations by sequestering TNF to its membrane receptors. The balance between TNF- $\alpha$ and the sTNF receptors apparently has an important role in the regulation of the TNF pathway. Recent studies have reported that TNFR2 is significantly correlated with insulin resistance, HOMA-R and BP. ${ }^{10,31} \mathrm{BMI}$ and HOMA-R were significantly greater in HT than in NT. Even if we restricted the inclusion criteria to BMI less than $28 \mathrm{~kg} \mathrm{~m}^{-2}$, the results were similar (data not shown). Therefore, higher sTNFR2 levels are likely to represent an augmented TNF pathway and inflammatory process, which lead to insulin resistance and severe hypertension.

We readily acknowledge that with so many false-positive reports having been published in genetic association studies, small numbers of the patients are frequently criticized. Although we cannot deny the statistical possibility of a type I error, a significant relationship between the genotype and the series of biologically related intermediate phenotypes supports our hypothesis. Although the process of estimating the prior probability includes subjectivity, the results of one positive case-control study and another larger marginal study indicate the prior probability of this situation as around 0.1 , not as 0.01 , according to the examples Wacholder et al. presented. ${ }^{15-17}$ As the odds ratio was 2.08 in this study, false-positive report probability is estimated as less than 0.5 , which is considered as a borderline threshold (power $=0.3$ ). How have we overcome the borderline threshold of false-positive report probability despite the small sample size? The association study using the EDP design could enhance the statistical power more than double when both the upper and lower selection areas were less than 10 percentile. ${ }^{18-20}$ Therefore, the power of this study is estimated as $>0.6$. Furthermore, although the probability of misclassification between case and control is an annoying issue in measuring phenotypes with large variations such as BP, the EDP design will decrease the possibility of misclassification. In addition, the allele frequency of CA16 is higher in our study than in the Speir study (30 vs. 23\%). Higher allele frequency is advantageous to detect statistically marginal significance. A weak point of this study lies in the process of sampling NT. Although we randomly selected age- and sex-matched NT who satisfied stringent criteria for the BP level $(\mathrm{SBP}<120$ and $\mathrm{DBP}<80 \mathrm{~mm} \mathrm{Hg})$ and the negative genetic predisposition to hypertension in the same University Hospital, some uncontrolled biases might have influenced the results. BMI was not matched between HT and NT because we focused on the EDP design according to BP levels and the genetic predispositions to hypertension. It remains unclear whether the observed association of the CA16 microsatellite polymorphism of the TNFR2 gene with HT was because of the direct effect of this polymorphism on BP or the indirect effects through confounding factors including the insulin resistance and the inflammation. Although our observation implied that the latter interpretation was more likely, this issue should be clarified in future studies. In some genes, the length of CA repeats, especially in intron 1, may have a role on gene expression and pathogenesis of genetic diseases. ${ }^{32,33}$ We cannot rule out the possibility that other genes in linkage disequilibrium with CA16 might be components of severe hypertension through the disturbed TNF pathway and insulin resistance. Our findings are limited to male severe hypertension, whereas it is extremely difficult to enroll female patients using the EDP design at a similar age. Menopause substantially influences blood pressure regulation. Therefore, we should investigate the association using other polymorphisms of the TNFR2 gene and other populations in the future.

In conclusion, insulin resistance is associated with severe hypertension, possibly through an altered TNF pathway. The CA16 micro- satellite polymorphism of the TNFR2 gene is a potential marker of severe hypertension with insulin resistance. A case-control association study using the EDP design is an efficient approach to re-explore the possible genetic association.

\section{CONFLICT OF INTEREST}

The authors declare no conflict of interest.

\section{ACKNOWLEDGEMENTS}

We thank Katsuaki Dan for his technical support with genotyping and Mai Iida and Naoko Ohara for their assistance in processing the samples. This study was supported by scientific research grants of the Ministry of Health, Labor and Welfare and of the Ministry of Education, Culture, Sports, Science and Technology.

1 DeFronzo RA, Ferrannini E. Insulin resistance. A multifaceted syndrome responsible for NIDDM, obesity, hypertension, dyslipidemia, and atherosclerotic cardiovascular disease. Diabetes Care 1991; 14: 173-194.

2 Ross R. Atherosclerosis-an inflammatory disease. N Engl J Med 1999; 340: 115-126.

3 Hansson GK. Inflammation, atherosclerosis, and coronary artery disease. N Eng/ J Med 2005; 352: 1685-1695.

4 Mahmud A, Feely J. Arterial stiffness is related to systemic inflammation in essential hypertension. Hypertension 2005; 46: 1118-1122.

5 Pietri P, Vyssoulis G, Vlachopoulos C, Zervoudaki A, Gialernios T, Aznaouridis K, Stefanadis C. Relationship between low-grade inflammation and arterial stiffness in patients with essential hypertension. J Hypertens 2006; 24: 2231-2238.

6 Wang TJ, Gona P, Larson MG, Levy D, Benjamin EJ, Tofler GH, Jacques PF, Meigs JB, Rifai N, Selhub J, Robins SJ, Newton-Cheh C, Vasan RS. Multiple biomarkers and the risk of incident hypertension. Hypertension 2007; 49: 432-438.

$7 \mathrm{Yu} \mathrm{YH}$, Ginsberg HN. Adipocyte signaling and lipid homeostasis: sequelae of insulinresistant adipose tissue. Circ Res 2005; 96: 1042-1052.

8 Fernandez-Real JM, Ricart W. Insulin resistance and chronic cardiovascular inflammatory syndrome. Endocr Rev 2003; 24: 278-301.

9 Hotamisligil GS, Arner P, Caro JF, Atkinson RL, Spiegelman BM. Increased adipose tissue expression of tumor necrosis factor-alpha in human obesity and insulin resistance. J Clin Invest 1995; 95: 2409-2415.

10 Fernandez-Real JM, Broch M, Ricart W, Casamitjana R, Gutierrez C, Vendrell J, Richart C. Plasma levels of the soluble fraction of tumor necrosis factor receptor 2 and insulin resistance. Diabetes 1998; 47: 1757-1762.

11 Aderka D, Engelmann H, Maor Y, Brakebusch C, Wallach D. Stabilization of the bioactivity of tumor necrosis factor by its soluble receptors. J Exp Med 1992; 175: 323-329.

12 Ohno Y, Suzuki H, Yamakawa H, Nakamura M, Otsuka K, Saruta T. Impaired insulin sensitivity in young, lean normotensive offspring of essential hypertensives: possible role of disturbed calcium metabolism. J Hypertens 1993; 11: 421-426.

13 Morii T, Ohno Y, Hirose H, Kawabe H, Ogata T, Hirao K, Eguchi T, Maruyama T, Kanno Y, Hayashi M, Saito I, Saruta T. Cellular insulin resistance in Epstein-Barr virus-transformed lymphoblasts from young insulin-resistant Japanese men. Metabolism 2005; 54: $370-375$.

14 Fernandez-Real JM, Vendrell J, Ricart W, Broch M, Gutierrez C, Casamitjana R, Oriola J, Richart C. Polymorphism of the tumor necrosis factor-alpha receptor 2 gene is associated with obesity, leptin levels, and insulin resistance in young subjects and diet-treated type 2 diabetic patients. Diabetes Care 2000; 23: 831-837.

15 Glenn CL, Wang WY, Benjafield AV, Morris BJ. Linkage and association of tumor necrosis factor receptor 2 locus with hypertension, hypercholesterolemia and plasma shed receptor. Hum Mol Genet 2000; 9: 1943-1949.

16 Speirs HJL, Wang WYS, Benjafield AV, Morris BJ. No association with hypertension of CLCNKB and TNFRSF1B polymorphisms at a hypertension locus on chromosome 1p36. J Hypertens 2005; 23: 1491-1496.

17 Wacholder S, Chanock S, Garcia-Closas M, El Ghormli L, Rothman N. Assessing the probability that a positive report is false: an approach for molecular epidemiology studies. J Natl Cancer Inst 2004; 96: 434-442.

18 Ohno Y, Tanase H, Nabika T, Otsuka K, Sasaki T, Suzawa T, Morii T, Yamori Y, Saruta T. Selective genotyping with epistasis can be utilized for a major quantitative trait locus mapping in hypertension in rats. Genetics 2000; 155: 785-792.

19 Van Gestel S, Houwing-Duistermaat JJ, Adolfsson R, van Duijn CM, Van Broeckhoven C. Power of selective genotyping in genetic association analyses of quantitative traits. Behav Genet 2000; 30: 141-146.

20 Zhang G, Nebert DW, Chakraborty R, Jin L. Statistical power of association using the extreme discordant phenotype design. Pharmacogenet Genomics 2006; 16: 401-413.

21 Lida M, Ueda K, Okayama A, Kodama K, Sawai K, Shibata S, Tanaka S, Keijnkai T, Horibe $\mathrm{H}$, Minowa M, Yanagawa $\mathrm{H}$, Hashimoto T. Impact of elevated blood pressure on mortality from all causes, cardiovascular diseases, heart disease and stroke among 
Japanese: 14 year follow-up of randomly selected population from Japanese-Nippon data 80. J Hum Hypertens 2003; 17: 851-857.

22 Tozawa M, Oshiro S, Iseki C, Sesoko S, Higashiuesato Y, Tana T, Ikemiya Y, Iseki K, Fukiyama K. Family history of hypertension and blood pressure in a screened cohort. Hypertens Res 2001; 24: 93-98.

23 Weidmann P, Bohlen L, de Courten M. Insulin resistance and hyperinsulinemia in hypertension. J Hypertens Supp/ 1995; 13: S65-S72.

24 Ikegami H, Yamato E, Fujisawa T, Hamada Y, Fujioka Y, Rakugi H, Higaki J, Murakami $\mathrm{H}$, Shimamoto K, Ogihara T. Analysis of candidate genes for insulin resistance in essential hypertension. Hypertens Res 1996; 19 (Suppl 1): S31-S34.

25 Poch E, Giner V, Gonzalez-Nunez D, Coll E, Oriola J, de la Sierra A. Association of the G protein beta3 subunit Tallele with insulin resistance in essential hypertension. Clin Exp Hypertens 2002; 24: 345-353.

26 Yamamoto J, Kageyama S, Nemoto M, Sasaki T, Sakurai T, Ishibashi K, Mimura A, Yokota K, Tajima N. PPARgamma2 pro12Ala polymorphism and insulin resistance in Japanese hypertensive patients. Hypertens Res 2002; 25: 25-29.

27 Olivier M, Hsiung CA, Chuang LM, Ho LT, Ting CT, Bustos VI, Lee TM, De Witte A, Chen YD, Olshen R, Rodriguez B, Wen CC, Cox DR. Single nucleotide polymorphisms in protein tyrosine phosphatase 1 beta (PTPN1) are associated with essential hypertension and obesity. Hum Mol Genet 2004; 13: 1885-1892.
28 Nophar Y, Kemper O, Brakebusch C, Englemann H, Zwang R, Aderka D, Holtmann H, Wallach D. Soluble forms of tumor necrosis factor receptors (TNF-Rs). The cDNA for the type I TNF-R, cloned using amino acid sequence data of its soluble form, encodes both the cell surface and a soluble form of the receptor. EMBO J 1990; 9: 3269-3278.

29 McCarron RM, Wang L, Siren AL, Spatz M, Hallenbeck JM. Monocyte adhesion to cerebromicrovascular endothelial cells derived from hypertensive and normotensive rats. Am J Physiol 1994; 267: H2491-H2497.

30 Aggarwal BB. Signalling pathways of the TNF superfamily: a double-edged sword. Nat Rev Immunol 2003; 3: 745-756.

31 Fernandez-Real JM, Lainez B, Vendrell J, Rigla M, Castro A, Penarroja G, Broch M, Perez A, Richart C, Engel P, Ricart W. Shedding of TNF-alpha receptors, blood pressure, and insulin sensitivity in type 2 diabetes mellitus. Am J Physiol Endocrinol Metab 2002; 282: E952-E959.

32 Agarwal AK, Giacchetti G, Lavery G, Nikkila H, Palermo M, Ricketts M, McTernan C, Bianchi G, Manunta P, Strazzullo P, Mantero F, White PC, Stewart PM. CA-Repeat polymorphism in intron 1 of HSD11B2: effects on gene expression and salt sensitivity. Hypertension 2000; 36: 187-194.

33 Brandt B, Meyer-Staeckling S, Schmidt H, Agelopoulos K, Buerger H. Mechanisms of egfr gene transcription modulation: relationship to cancer risk and therapy response. Clin Cancer Res 2006; 12: 7252-7260. 